DOI: $10.15593 / 2224-9354 / 2019.1 .17$

УДК 336-028.27

\author{
И.В. Ёлохова, М.И. Ахметова, А.В. Крутова, А.В. Тетенова \\ ПОДХОДЫ К ОПРЕДЕЛЕНИЮ ПРАВОВОГО СТАТУСА \\ КРИПТОВАЛЮТ В ВЕДУЩИХ СТРАНАХ МИРА
}

\begin{abstract}
Статья посвящена вопросам законодательного регулирования основных составляющих цифровой экономики: криптовалют, ICO (первичное размещение монет), блокчейна и майнинга, охарактеризован их правовой статус, специфика их использования и институциональное регулирование на примере таких крупных стран, как Россия, США и Китай. Авторами также проведен анализ рынка криптовалют ведущих стран мира, на основе которого выявлены преимущества и недостатки использования криптовалюты как денежных средств, актива и иного имущества. Рассмотрены причины роста внимания мировой общественности к цифровой валюте. Показана история становления криптовалюты. Рассмотрены главные события, предопределившие ситуацию на рынке криптовалют, с точки зрения разных институтов ведущих стран мира. Проанализированы подходы ряда федеральных ведомств по отношению к самой криптовалюте как к особому типу активов, майнингу как к виду предпринимательской деятельности, ICO как к инструменту привлечения инвестиций, блокчейну как к технологии. В результате исследования выявлены основные проблемы и препятствия, возникающие на пути внедрения криптовалюты в качестве денежной единицы в экономику России. Кроме того, рассмотрены перспективы использования блокчейн-технологий в различных социально-экономических сферах жизнедеятельности, связанных как с коммерческим применением, так и государственным и муниципальным управлением. Отмечена положительная позиция в отношении технологии блокчейн со стороны основных институциональных игроков финансового рынка. Выявлены причины, в связи с которыми в России, скорее всего, не будет создано препятствий для совершенствования фринансовой системы. Предложен возможный сценарий развития криптоиндустрии в России на основе опыта зарубежных стран в данной сфере.

Ключевые слова: цифровая экономика, электронные деньги, криптовалюта, биткоин, первоначальное размещение монет, блокчейн, майнинг.
\end{abstract}

В условиях продолжающегося мирового финансово-экономического кризиса, снижения доверия юридических и физических лиц к банковской системе и высокой волатильности валютных отношений актуальными становятся альтернативные электронные денежные системы [1, с. 58]. Наиболее известная электронная валюта биткоин (bitcoin) защищена системой криптографического

(С Ёлохова И.В., Ахметова М.И., Крутова А.В., Тетенова А.В., 2019

Ёлохова Ирина Владимировна - д-р экон. наук, професссор, заведующая кафедрой экономики и финансов ФГБОУ ВО «Пермский национальный исследовательский политехнический университет», e-mail: elohova.iv@gmail.com.

Ахметова Марина Игоревна - канд. экон. наук, доцент кафедры экономики и финансов ФГБОУ ВО «Пермский национальный исследовательский политехнический университет», e-mail: miahmetova@gmail.com.

Крутова Александра Валентиновна - канд. экон. наук, доцент кафедры экономики и финансов ФГБОУ ВО «Пермский национальный исследовательский политехнический университет», e-mail: alexkrutova@yandex.ru.

Тетенова Анастасия Вячеславовна - студентка дневного отделения группы ФПП-14-1б, ФГБОУ ВО «Пермский национальный исследовательский политехнический университет», e-mail: anastasia.tetenova@mail.ru. 
кодирования и потому ее часто называют криптовалютой. В технологию блокчейн изначально заложена безопасность на уровне базы данных. Блокчейн это распределенная система хранения данных, записи которых невозможно подделать. Концепцию цепочек блоков предложил в 2008 году некий Сатоши Накамото (Satoshi Nakamoto) [2]. Впервые эта концепция реализована в 2009 году как компонент цифровой валюты - биткоина, где блокчейн играет роль главного общего реестра для всех операций с биткоинами.

Криптоиндустрия стремительно развивается, привлекая инициативных предпринимателей и достаточно большой интеллектуальный ресурс. Способ привлечения финансирования в стартапы через размещение новых криптовалют ICO (Initial Coin Offering), по аналогии с публичным размещением акций IPO (Initial Public Offering), становится все более популярным в мире за последние три года.

В связи с разнообразием существующих в международной практике подходов к новым электронным системам авторы задались целью оценить правовой статус элементов цифровой экономики: криптовалют, ICO, блокчейна и майнинга на примере таких крупнейших мировых держав, как Россия, США и Китай.

Для достижения поставленной цели авторы статьи рассмотрели четыре основных элемента цифровой экономики с позиции государственного институционального регулирования финансовых и экономических отношений, а также ключевых фигур власти и бизнеса.

Правовой статус криптовалют, в частности системы «Биткоин», значительно различается в разных странах. В ряде стран официально разрешены операции с криптовалютами. Обычно они рассматриваются как товар или инвестиционный актив, или деньги, и для целей налогообложения подчинены соответствующему законодательству [3].

Позиции разных государств в отношении биткоина разделяются, но в целом они попадают в следующие три группы:

1. Страны, регулируюшие криптовалюту: Япония, США, Великобритания, Сингапур, Канада, Гонконг. Перечисленные страны уже поместили биткоин-транзакции в правовое поле.

2. Страны, находящиеся на пути регулирования криптовалют. Ряд стран разрабатывают нормативно-правовую базу с целью активного внедрения цифровой валюты в экономику (Австралия, Бельгия, Бразилия, Колумбия, Хорватия, Чешская Республика, Кипр, Дания, Франция, Германия, Израиль, Италия и др.).

3. Страны, запрещзающие криптовалюту. Страны, считающие ее нелегальной и пытающиеся в настоящее время запретить или ограничить ее использование: Бангладеш, Боливия, Китай, Эквадор, Исландия, Индонезия, Кыргызстан, Ливан, Венесуэла, Таиланд, Вьетнам.

Рассмотрим особенности определения правового статуса криптовалют и их использования в разных странах. 
Соединенные Штаты Америки. Рассмотрим историю и факты принятия элементов цифровой экономики в США. В марте 2013 года комиссия по финансовым преступлениям FinCEN объявила о том, что операции по обмену любых криптовалют на фиатные деньги должны регулироваться так же, как и операции по обмену фиатных денег между собой (например, доллары на евро). Не только биткоин-биржи, но и обменные пункты должны зарегистрироваться в качестве поставщиков финансовых услуг (Money Service Business) и сообщать о подозрительных транзакциях в органы правопорядка.

В официальных отчетах Всемирного банка и ФБР биткоин считают «виртуальной валютой». По классификации комиссии FinCEN при министерстве финансов США биткоин относят к «децентрализованным виртуальным валютам» [4]. Комиссия по ценным бумагам и биржам США приняла решение приравнять ICO к ценным бумагам. Компании, которые не зарегистрируют выпуск криптовалюты или ICO, будут наказаны.

В августе 2013 года судья Восточного округа штата Техас (США) принял следующее решение. Поскольку биткоины можно использовать в качестве денег для оплаты за товары или обменять на обычные валюты, такие как доллар США, евро, иена или юань, то биткоин является валютой или формой денег.

25 марта 2014 года Служба внутренних доходов США выпустила руководство по налогообложению операций с биткоинами и другими виртуальными валютами. Майнеры, добывающие биткоины на собственном оборудовании, также подлежат налогообложению. Майнер обязан включить справедливую рыночную стоимость добытой криптовалюты в свой годовой валовой доход.

Различается правовая политика по отношению к криптовалютам в штатах страны. В штате Нью-Йорк осуществляется лицензирование деятельности лиц, занимающихся оборотом криптовалют, лицензия стоит около \$5000. В Калифорнии приняты одобренные ранее Сенатом штата поправки к законодательству, объявляющие биткоин и другие криптовалюты «легальным средством платежа». Данный закон позволяет проводить любые транзакции на территории штата в любой электронной валюте, в том числе в биткоинах [5].

Таким образом, США в настоящий момент времени институционально признали все объекты цифровой экономики и начали регулировать данный процесс законодательно, в том числе и в области налогообложения.

Китай. Напротив действиям в США, связанным с легализацией криптовалюты, правительство Китая стало не в состоянии регулировать новый свободный мир криптовалюты, хотя ее курс значительно вырос из-за спекулятивного спроса на монеты именно в этой стране. Рассмотрим, как государственные органы Китая по-разному регулируют вопрос, связанный с определением правового статуса криптовалют и их использования.

В 2013 году стоимость биткоина возросла в 89 раз, что обусловило повышенное внимание к электронной валюте со стороны китайских инвесторов, как 
к альтернативному платежному средству. В связи с этим Народный банк Китая (НБК) наложил запрет на проведение операций с биткоином финансовыми компаниями, в том числе под запрет попала публикация котировок, а также страхование финансовых продуктов, связанных с этой криптовалютой. По данным Интерфакс, НБК обосновал данный запрет отсутствием юридического статуса биткоина как валюты. При этом запрет не распространялся на физических лиц, которые могли использовать биткоин в интернет-транзакциях, принимая на себя все риски, связанные с использованием данного платежного средства [6].

Ключевым событием 2017 года стал запрет Народным банком Китая на проведение ICO для китайских компаний. Кроме того, НБК обязал местные ICO-платформы и компании, которые уже выпустили токены, осуществить возврат всех привлеченных средств [7].

Согласно официальной позиции НБК, все ICO в государстве с 4 сентября 2017 года начали считаться незаконными. В перспективе регулятор намерен наказывать за подобные нарушения. Он пригрозил правовыми последствиями, в том числе за уже завершенные ICO.

По сведениям китайского Национального комитета экспертов по технологиям финансовой безопасности в Интернете, по состоянию на июль 2017 года, в Китае функционировали 43 ICO-платформы, уже к 18 июля завершены 65 ICO, размещение токенов позволило компаниям привлечь 398 млн долл. [8].

Рынок криптовалют встретил новость о запрете ICO в Китае весьма негативно. Согласно сведениям Coindesk, биткоин упал на торгах на 5 \%, а эфириум потерял $15 \%$ стоимости [9].

Введение данного ограничения в Китае спровоцировало коррекцию, масштаб которой по биткоину доходил до 40 \%, но длилось это недолгое время. Руководитель CryptoFund Александр Бояринцев обозначил, что введение барьеров в отдельно взятой стране приводит к перетеканию капитала на другие рынки [9]. Это и случилось в данной ситуации. Аналитик Forex Club Ирина Рогова отметила, что китайские трейдеры перешли на биржи Гонконга и Японии. В связи с этим объемы торгов гонконгской биржи Gatecoin подскочили на 24 \%. Кроме того, Япония стала принимать у себя китайские ICO-стартапы [10].

24 октября 2017 года в Китае закончился ХІХ съезд Национального конгресса коммунистической партии Китая. По итогам съезда были отменены некоторые временные правила и установки. Предположительно в их число вошел и запрет на торговлю биткоин [11].

Наряду с действиями Пекина относительно закрытия бирж биткоина и запрета продаж токенов и ICO отметим, что Китай стремится к распространению технологии блокчейн. Ведется активная работа по созданию распределенного реестра, также Министерство информационных технологий Китая осуществляет поддержку лаборатории блокчейна, которая создана уже после запретов на работу бирж криптовалют. Кроме того, запреты в Китае связы- 
ваются рядом специалистов с готовностью НБК к выпуску собственной государственной криптовалюты, о чем свидетельствует создание исследовательского института по изучению криптовалют [11].

Таким образом, события, происходящие в сфере криптовалют в зарубежных странах, могут послужить опытом для определения статуса криптовалюты и ICO в России, так как на сегодняшний день отсутствует правовое регулирование деятельности сети биткоин и операций с криптовалютами.

Российская Федерация. Характерная особенность государственной политики в области криптовалют в России состоит в том, что ее курс формируется исходя из позиций ряда федеральных ведомств (Центральный банк, Министерство финансов, Росфинмониторинг, Министерство экономического развития, Генеральная прокуратура), у которых нет единой позиции.

В начале 2014 года Центральный банк отнес биткоин и другие виртуальные валюты к понятию «денежного суррогата», которые будут иметь статус сомнительных операций по «отмыванию доходов» и преступной деятельности. Глава Центрального банка Российской Федерации Эльвира Набиуллина считает нецелесообразным легализацию криптовалют на российских биржах и определяет «криптовалюту» как цифровой актив, а не виртуальную валюту [12], но не отрицает и перспективы развития технологии блокчейна, лежащей в его основе. По ее словам, регулятор рассматривает возможность создания платформы для передачи финансовых сообщений с использованием блокчейна, а также создания на его основе национальной криптовалюты [13].

С 2014 года по март 2016 года Министерство финансов признавало криптовалюты как «денежный суррогат» и ужесточало меры по операциям с ними от штрафов до лишения свободы [14]. Однако уже в августе 2017 года Министерство финансов признало необходимость внесения поправок в законодательство по операциям с криптовалютами в связи с их активным использованием и легализацией в некоторых ведущих странах мира (США, Швейцария, Япония) [15].

По словам президента российской ассоциации криптовалют и блокчейна Юрия Припачкина, ICO серьезно удешевляет процесс привлечения средств и ускоряет его, а также ICO снимает целый ряд барьеров между деньгами инвесторов и эмитентами, и будет служить дальнейшему развитию экономики [16].

Глава Сбербанка Герман Греф отметил, что блокчейн - такая взрывная технология, внедрение которой необходимо. По его словам, данная технология уже используется Сбербанком для реализации ряда процессов. К тому же, в 2015 году он сообщил, что обладает небольшим количеством криптовалюты [17].

По словам Президента РФ Владимира Путина, недопустимо создание барьеров для совершенствования финансовой системы, а необходимо формирование мер по регулированию. В связи с этим задачей Минфина является разработка рамочного законопроекта о регулировании криптовалют к концу 
2017 года. Также Правительству РФ и Центральному банку необходимо изменить законодательство РФ о регулировании публичного привлечения криптовалют и денежных средств путем размещения токенов (ICO) по аналогии с регулированием первичного размещения ценных бумаг до 1 июля 2018 года в рамках реализации программы «Цифровая экономика» [18]. Помимо этого, глава государства поручил им разработать требования к организации «майнинга», определиться с его налогообложением и регистрацией майнеров [19].

2018 год может стать знаковым для криптовалютного рынка в России. Правительство России рассчитывает легализовать в стране биткоин и другие криптовалюты с целью снижения рисков, связанных с незаконными переводами и «отмыванием денег», как пояснил заместитель министра финансов Алексей Моисеев [20]. Государственные органы заинтересованы в развитии эффективных технологий на основе блокчейн.

\section{Список литературы}

1. Прокин В.В. Актуальные проблемы стратегического развития российской экономики // Вестник Пермского национального исследовательского политехнического университета. Социально-экономические науки. - 2015. № $1 .-$ C. $58-63$.

2. Что такое блокчейн? Расскажем простыми словами [Электронный реcypc] // Coinspot. - URL: https://coinspot.io/ (дата обращения: 28.10.2017).

3. Ларина Е., Овчинский В.С. Анатомия биткоинов. Ч. VII. Биткоин и другие криптовалюты: Итоги [Электронный ресурс] // Институт высокого коммунитаризма. - URL: http://communitarian.ru/ (дата обращения: 28.10.2017).

4. Арянова Т. Комиссия по ценным бумагам и биржам США решила приравнять ICO к выпуску ценных бумаг [Электронный ресурс] // Insider PRO. - URL: https://ru.insider.pro/ (дата обращения: 28.10.2017).

5. Блокчейн ICO - угроза третьей мировой? [Электронный ресурс] // Forbes. - URL: http://www.forbes.ru/ (дата обращения: 28.10.2017).

6. ЦБ Китая запретил банкам операции с Bitcoin [Электронный ресурс] // Ведомости. - URL: https://www.vedomosti.ru/ (дата обращения: 29.10.2017).

7. Астапкович В. В Китае заявили, что криптовалюты все чаще используют для отмывания денег [Электронный ресурс] // PИA Новости. - URL: https://ria.ru/ (дата обращения: 29.10.2017).

8. «Переполох в Китае»: криптовалютный рынок - ниже 100 млрд долл. [Электронный pecypc] // Coinspot. - URL: https://coinspot.io/ (дата обращения: 30.10.2017).

9. Гатинский А. Центробанк Китая запретил ICO [Электронный ресурс] // РосБизнесКонсалтинг. - URL: http://www.rbc.ru/ (дата обращения: 30.10.2017).

10. Биткоин взлетел на $60 \%$ за месяц и превысил $\$ 5000$ [Электронный pecypc] // UDF.BY. - URL: http://udf.by/ (дата обращения: 30.10.2017). 
11. Китай добивает криптовалюты [Электронный pecypc] // Breaking Crypto News. - URL: https://freedman.club/ (дата обращения: 31.10.2017).

12. Минфин: в 2018 г. в России легализуют биткоины [Электронный ресурс] // Издание о высоких технологиях CNEWS. - URL: http://www.cnews.ru/ (дата обращения: 27.10.2017).

13. Селиверстова Н. Виртуальное будущее: ЦБ начал разработку национальной криптовалюты [Электронный ресурс] // PИА Новости. -URL: https://ria.ru/ (дата обращения: 27.10.2017).

14. Цифровая лавина: почему рынок ICO растет так быстро [Электронный ресурс] // РосБизнесКонсалтинг. - URL: http://www.rbc.ru/ (дата обращения: 30.10 .2017$)$.

15. Балашова А., Ли И. В России решили легализовать привлечение денег на ICO [Электронный ресурс] // РосБизнесКонсалтинг. - URL: http://www.rbc.ru/ (дата обращения: 30.10.2017).

16. Минэкономразвития предложило разрабатывать законы о криптовалюте на основе опыта «правовых песочниц» [Электронный ресурс] // Портал о частных инвестициях и личных финансах. - URL: http://www.finanz.ru/ novosti/ (дата обращения: 31.10.2017).

17. Герман Греф призвал к легализации биткоина и других криптовалют в России [Электронный ресурс] // RUSBASE. - URL: https://rb.ru/ (дата обращения: 31.10.2017).

18. Левашенко А., Коваль А., Ермохин И. Правовые аспекты ITO/ICO [Электронный ресурс] // Российский центр компетенций и анализа стандартов OЭCP. - URL: http://www.ranepa.ru/ (дата обращения: 29.10.2017).

19. Зачем России криптовалюта [Электронный ресурс] // АГИТ ПОЛК. URL: http://agitpolk.ru/ (дата обращения: 29.10.2017).

20. Биткоин не для всех: Минфин предложил запретить «обычным людям» покупать криптовалюту [Электронный ресурс] // РосБизнесКонсалтинг. URL: http://www.rbc.ru/ (дата обращения: 30.10.2017).

\section{References}

1. Prokin V.V. Aktual'nye problemy strategicheskogo razvitiia Rossiiskoi ekonomiki [Current problems of strategic development of the Russian economy]. PNRPU Sociology and Economics Bulletin, 2015, no. 1, pp. 58-63.

2. Chto takoe blokchein? Rasskazhem prostymi slovami [What is blockchain? In simple words]. Coinspot, available at: https://coinspot.io/ (accessed 28 October 2017).

3. Larina E., Ovchinskii V.S. Anatomiia bitkoinov. Ch. VII. Bitkoin i drugie kriptovaliuty: Itogi [Bitcoin's anatomy. P.VII. Bitcoin and other cryptocurrencies: The results]. Institut vysokogo kommunitarizma, available at: http://communitarian.ru/ (accessed 28 October 2017).

4. Arianova T. Komissiia po tsennym bumagam i birzham SShA reshila priravniat' ICO k vypusku tsennykh bumag [US Securities and Exchange Commis- 
sion decided to equate ICO with securities issue]. Insider PRO, available at: https://ru.insider.pro/ (accessed 28 October 2017).

5. Blokchein ICO - ugroza tret'ei mirovoi? [ICO Blockchain - a threat of the Third World War?]. Forbes, available at: http://www.forbes.ru/ (accessed 28 October 2017).

6. TsB Kitaia zapretil bankam operatsii s Bitcoin [The People's Bank of China has banned operations with Bitcoins]. Vedomosti, available at: https://www.vedomosti.ru/ (accessed 29 October 2017).

7. Astapkovich V. V Kitae zaiavili, chto kriptovaliuty vse chashche ispol'zuiut dlia otmyvaniia deneg [China argues that cryptocurrency is increasingly used for money-laundering]. RIA Novosti, available at: https://ria.ru/ (accessed 29 October 2017).

8. "Perepolokh v Kitae": kriptovaliutnyi rynok - nizhe 100 mlrd. doll. ["Commotion in China": Cryptocurrency market amounts to less than $\$ 100$ billion]. Coinspot, available at: https://coinspot.io/ (accessed 30 October 2017).

9. Gatinskii A. Tsentrobank Kitaia zapretil ICO [The People's Bank of China has banned ICO]. RosBiznesKonsalting, available at: http://www.rbc.ru/ (accessed 30 October 2017).

10. Bitkoin vzletel na $60 \%$ za mesiats i prevysil $\$ 5000$ [Bitcoin soared by $60 \%$ in a month to beat $\$ 5000]$. UDF.BY, available at: http://udf.by/ (accessed 30 October 2017).

11. Kitai dobivaet kriptovaliuty [China is killing cryptocurrency]. Breaking Crypto News, available at: https://freedman.club/ (accessed 31 October 2017).

12. Minfin: $\mathrm{v} 2018 \mathrm{~g}$. $\mathrm{v}$ Rossii legalizuiut bitkoiny [The Ministry of finance of the Russian Federation: In 2008 bitcoins will be legalized in Russia]. Izdanie o vysokikh tekhnologiiakh CNEWS, available at: http://www.cnews.ru/ (accessed 27 October 2017).

13. Seliverstova N. Virtual'noe budushchee: TsB nachal razrabotku natsional'noi kriptovaliuty [Virtual future: A Central bank began to develop national cryptocurrency]. RIA Novosti, available: https://ria.ru/ (accessed 27 October 2017).

14. Tsifrovaia lavina: pochemu rynok ICO rastet tak bystro [Digital avalanche: Why is ICO-market growing so fast]. RosBiznesKonsalting, available at: http://www.rbc.ru/ (accessed 30 October 2017).

15. Balashova A., Li I. V Rossii reshili legalizovat' privlechenie deneg na ICO [Russia legalizes attracting money for ICO]. RosBiznesKonsalting, available at: http://www.rbc.ru/ (accessed 30 October 2017).

16. Minekonomrazvitiia predlozhilo razrabatyvat' zakony o kriptovaliute na osnove opyta "pravovykh pesochnits" [The Ministry of Economic Development and Trade offers to develop laws on cryptocurrency using experience of "legal sandboxes"]. Portal o chastnykh investitsiiakh i lichnykh finansakh, available at: http://www.finanz.ru/novosti/ (accessed 31 October 17).

17. German Gref prizval k legalizatsii bitkoina i drugikh kriptovaliut v Rossii [Herman Gref calls for legalizing bitcoins and other cryptocurrencies in Russia]. RUSBASE, available at: https://rb.ru/ (accessed 31 October 2017). 
18. Levashenko A., Koval' A., Ermokhin I. Pravovye aspekty ITO/ICO [Legal aspects of ITO/ICO]. Rossiiskii tsentr kompetentsii $i$ analiza standartov OESR, available at: http://www.ranepa.ru/ (accessed 29 October 2017).

19. Zachem Rossii kriptovaliuta [Does Russia need cryptocurrency?]. AGIT POLK, available at: http://agitpolk.ru/ (accessed 29 October 2017).

20. Bitkoin ne dlia vsekh: Minfin predlozhil zapretit' "obychnym liudiam" pokupat' kriptovaliutu [Bitcoin is not for everybody: The Ministry of Finance suggests to ban purchase of cryptocurrency by ordinary people]. RosBiznesKonsalting, available at: http://www.rbc.ru/ (accessed 30 October 2017).

Оригинальность $89 \%$

Получено 10.04.2018 Принято 10.05.2018 Опубликовано 03.04.2019

\author{
I.V. Yolokhova, M.I. Akhmetova, A.V. Krutova, A.V. Tetenova
}

\title{
APPROACHES TO DETERMINING LEGAL STATUS OF CRYPTOCURRENCIES IN THE WORLD'S LEADING COUNTRIES
}

\begin{abstract}
The article is devoted to the issues of legal regulation of the main components of the digital economy: cryptocurrency, ICO (initial placement of coins), blockchain and mining, characterizing their legal status, the specifics of their use and institutional regulation by the example of such large countries as Russia, the United States and China. The authors also analyzed the cryptocurrency market of the world's leading countries, which helped to identify the advantages and disadvantages of using cryptocurrency as cash, asset and other property. The reasons for the world community's growing attention to digital currency are considered. The history of cryptocurrency formation is shown. The main events that predetermined the situation in the market of cryptocurrencies from the point of view of different institutions of the leading countries are considered. The study also covers the approaches of some federal agencies to cryptocurrency as a special type of assets, mining as a type of entrepreneurial activity, ICO as a tool to attract investment, blockchain as a technology. The research identified the main problems and obstacles hindering the introduction of cryptocurrency as a monetary unit in the Russian economy. Besides, the prospects were considered of using blockchain technologies in various social and economic spheres connected with commercial application, as well as with state and municipal management. There is a positive attitude towards blockchain technology on the part of the main institutional players of the financial market. The reasons for which Russia is unlikely to create obstacles to improving its financial system have been identified. A possible scenario for the development of the cryptographic industry in Russia based on the experience of foreign countries in this field is put forward.

Keywords: digital economy, electronic money, cryptocurrency, bitcoin, initial placement of coins, blockchain, mining.
\end{abstract}

Irina V. Yolokhova - Doctor of Economics, Professor, Head of the Department of Economics and Finance, Perm National Research Polytechnic University, e-mail: elohova.iv@gmail.com.

Marina I. Akhmetova - Candidate of Economic Sciences, Associate Professor, Department of Economics and Finance, Perm National Research Polytechnic University, e-mail: miahmetova@gmail.com.

Aleksandra V. Krutova - Candidate of Economic Sciences, Associate Professor, Department of Economics and Finance, Perm National Research Polytechnic University, e-mail: alexkrutova@yandex.ru.

Anastasiya V. Tetenova - Undergraduate Student, Department of Economics and Finance, Perm National Research Polytechnic University, e-mail: anastasia.tetenova@mail.ru.

$$
\text { Received 10.04.2018 Accepted 10.05.2018 Published 03.04.2019 }
$$

